\title{
Analysis of macro and micro elemental composition of different extracts and finished products of the medicinal Herb - Terminalia bellirica
}

\author{
Conjeevaram J. Gunasekar ${ }^{1}$, Imad A. Abu-Yousef ${ }^{2}$, Srinivasan Narasimhan ${ }^{1}$ and \\ Amin F. Majdalawieh ${ }^{2, *}$ \\ ${ }^{1}$ Asthagiri Herbal Research Foundation, 162A, Perungudi Industrial Estate, Perungudi, Chennai, India 600096 \\ ${ }^{2}$ Department of Biology, Chemistry, and Environmental Sciences, College of Arts and Sciences, American \\ University of Sharjah, P.O. Box 26666, Sharjah, United Arab Emirates
}

\begin{abstract}
Terminalina bellirica is considered to be a sacred plant with five distinctive tastes (sweet, sour, salty, bitter, and pungent). It stimulates the proper functioning of the digestive system, sensory organs and it is very effective in treating several medical conditions. Four types of extracts were prepared (aqueous extracts of $T$. bellirica fruit, alcoholic extract of $T$. bellirica fruit, alcoholic extract of seed oil from $T$. bellirica nuts, and alcoholic extract of $T$. bellirica seed kernel). The elemental composition of $T$. bellirica was determined by ICPOES. Macro elements like Ca (calcium), $\mathrm{Na}$ (sodium), and $\mathrm{K}$ (potassium) were found to be abundant in the studies samples. The quantity of $\mathrm{Ca}, \mathrm{Na}$, and $\mathrm{K}$ in the aqueous extracts of $T$. bellirica fruit, finished products of $T$. bellirica, alcoholic extract of $T$. bellirica fruit, alcoholic extract of seed oil from T. bellirica nuts, and alcoholic extract of T. bellirica seed kernel was found to be (723.51-787.39, 347.80-478.90, 50.72, 120, and $300 \mathrm{mg} / \mathrm{kg}),(603.45-$ $636.79,241.76-370.00,9.58,180$, and $200 \mathrm{mg} / \mathrm{kg})$, and $(151.23-165.73,132.70-154.40,4.26,200$, and 1,150 $\mathrm{mg} / \mathrm{kg}$ ), respectively. An $\mathrm{Na} / \mathrm{K}$ ratio $<1.0$ could prevent high blood pressure. The $\mathrm{Na} / \mathrm{K}$ ratio in the alcoholic extract of $T$. bellirica fruit was found to be 0.51 . Similarly, a $\mathrm{Ca} / \mathrm{P}$ ratio $>1.0$ is biologically relevant as a $\mathrm{Ca} / \mathrm{P}$ ratio $<0.5$ correlates with several health problems. The $\mathrm{Ca} / \mathrm{P}$ ratio in the alcoholic extract of $T$. bellirica fruit was found to be 6.68 . Hence, the measured $\mathrm{Na} / \mathrm{K}$ and $\mathrm{Ca} / \mathrm{P}$ ratios are in agreement with the recommended ratios. Our study supports the claims that $T$. bellirica extracts and finished products are of considerable therapeutic value for the prevention and/or treatment of various medical conditions. Moreover, the findings of our study will be helpful to ensure the quality and verify purification of natural products in different ayurvedic formulations.
\end{abstract}

Keywords: $T$. bellirica, microwave digestion, ICP-OES, trace elements, $\mathrm{Na} / \mathrm{K}$ ratio.

\section{Introduction}

Bellirica Myrobalan is commonly known as Bibitaki in Sanskrit and Bahera by local name which is an edible plant distributed throughout the central Asia ${ }^{1}$. It has been used as a folk medicine for more than thousands of years in Asia due to its tonic effects ${ }^{2}$. Bibitaki is a traditional name given to $T$. bellirica, which is one of the best single herbs controlling Kapha and it is well reputed as rasayana in Ayurvedic medicine. In Hindu language, Bibitaki means "fearless", and T. bellirica is considered a sacred herb among Hindu religious people of North India. It was introduced in Europe as an herbal medicine by Arabs. Recent research studies identified interesting phytochemicals present in $T$. bellirica, which may explain the reported biological activities of this plant's extracts and their use in traditional medicine ${ }^{3}$. Similarly, recent reports also highlighted the medicinal potential of certain Terminalia species *Corresponding author: Amin F. Majdalawieh Email address: amajdalawieh@aus.edu DOI: http://dx.doi.org/10.13171/mjc01912031128afm cultivated in Africa, Australia, and America ${ }^{4}$. It is known to possess medicinal activities such as analgesic, antioxidant, hepatoprotective, antibacterial, anti-cancer, and immunomodulatory activities ${ }^{5}$.

Accumulation of stones or calculi in the urinary, digestive, and respiratory tracts could be removed or expelled by the use of $T$. bellirica aqueous extract ${ }^{6}$. It is considered to be the strong rejuvenator to the human body and takes care of voice, vision and hair growth ${ }^{7}$. Because of its dual behavior like laxative and astringent and hence it purges the bowels and also toning the tissues of the digestive tract simultaneously.

It is one of the constituents of the famous preparation "Triphala", which finds use in a wide array of therapeutic areas ranging from hair care, laxative, headache, leucorrhoea, liver diseases to gastro-

Received September 29, 2019 Accepted November 4, 2019 Published December 3, 2019 
intestinal complaints ${ }^{8,9}$. Its fruit has been used in traditional medicine for anemia, asthma, cancer, colic, constipation, diarrhea, dysuria, headache, hypertension, inflammations, and rheumatism ${ }^{10,11}$. The leaves and fruits of $T$. bellirica possess antioxidant activity ${ }^{12,13}$. The aqueous and alcoholic extracts of the individual constituents of $T$. bellirica were shown to improve macrophage functions with regard to free radical scavenging and reactive oxygen species neutralization ${ }^{10,14}$. Surprising results were obtained when using ophthalmic drops (herbal eye drops) containing $T$. bellirica (Gaertn.) fruit-bearing part, displaying myocardial depressive activity especially in the case of myopia, pterygium, corneal opacity, unripe cataract, as well as other acute and chronic conditions ${ }^{15}$. Hypercholesterolemic animals showed marked reduction in their lipid levels when administered with $T$. bellirica ${ }^{16}$. Most recent research studies revealed that $T$. bellirica has the ability to lower the lipid levels in the liver and heart of the human body ${ }^{17}$. The risk associates with heart and liver is well protected due its strong ability in preventing heart and liver fat congestions.

Glucoside, tannins, gallic acid, ellagic acid, ethyl gallate, galloyl glucose, chebulanic acid are the main active phytoconstituents of medicinal importance. These phytoconstituents are responsible for many of the reported pharmacological roles ${ }^{18,19}$. Other studies revealed that extracts of $T$. bellirica leaves are of important therapeutic value as they exhibit antioxidant and anti-fungal activities ${ }^{20,21}$.

The therapeutic nature of $T$. bellirica could also be looked in terms of some essential elements present in it. Macro elements like $\mathrm{Ca}, \mathrm{Mg}, \mathrm{Na}$, and $\mathrm{K}$ are present in abundant quantities and are very unique when compared to other Terminalia species. In this study, the aqueous and alcoholic extracts of T. bellirica fruit and alcoholic extracts of T. bellirica seed oil and seed kernel were subjected to elemental determination by Inductively Coupled Plasma instrument and the elemental profile was created and calculated the concentration of each element and mean values were determined and tabulated and also regression analysis was performed for the data collected for each element.

\section{Material and Methods}

\subsection{Collection of Samples}

Well-matured, healthy, and dried fruits of $T$. bellirica were collected from different locations in India (April to June) and its mineral contents were quantified using ICP-OES.

Source I: Tambaram, India $\left(12^{\circ} 55^{\prime} 22.4940^{\prime \prime} \mathrm{N}\right.$ and $\left.80^{\circ} 7^{\prime} 38.8452^{\prime \prime} \mathrm{E}\right)$

Source II: Bangalore, India $\left(12.9716^{\circ} \mathrm{N}\right.$ and $\left.77.5946^{\circ} \mathrm{E}\right)$

Source III: Coimbatore, India $\left(11^{\circ} 0^{\prime} 16.4016^{\prime \prime} \mathrm{N}\right.$ and $\left.76^{\circ} 57^{\prime} 41.8752^{\prime \prime} \mathrm{E}\right)$

Source IV: Nagpur, India $\left(21^{\circ} 8^{\prime} 47.8788^{\prime \prime} \mathrm{N}\right.$ and 79॰ 5' 19.8960" E)

The standard aqueous extracts of $T$. bellirica (TBEs) are shown in Table 1. The finished products consisting of $T$. bellirica as a major ingredient (TBFs) are shown in Table 2.

Table 1. Standard aqueous extracts of T. bellirica (TBEs).

\begin{tabular}{|c|c|c|c|}
\hline Code & Source & Mass $(\mathbf{g})$ & Volume $(\mathbf{m l})$ \\
\hline TBE-1 & Tambaram & 1.2384 & 50.0 \\
\hline TBE-2 & Bangalore & 1.2276 & 50.0 \\
\hline TBE-3 & Coimbatore & 1.2143 & 50.0 \\
\hline TBE-4 & Nagpur & 1.2198 & 50.0 \\
\hline
\end{tabular}

Table 2. Finished products consisting of T. bellirica as a major ingredient (TBFs).

\begin{tabular}{|c|c|c|c|}
\hline Code & Source & Mass $(\mathbf{g})$ & Volume $(\mathbf{m l})$ \\
\hline TBF-1 & Chennai & 1.2303 & 50.0 \\
\hline TBF-2 & Coimbatore & 1.2163 & 50.0 \\
\hline TBF-3 & Bangalore & 1.2414 & 50.0 \\
\hline
\end{tabular}

\subsection{Solutions and Reagents}

Standard solutions were prepared by diluting individual metal standard solution $(1,000 \mu \mathrm{g} / \mathrm{ml})$ procured from BDH Middle East L.L.C. with $1.0 \mathrm{M}$ $\mathrm{HNO}_{3}$. The four types of extracts (aqueous extracts of $T$. bellirica fruit, alcoholic extract of $T$. bellirica fruit, alcoholic extract of seed oil from $T$. bellirica nuts, and alcoholic extract of $T$. bellirica seed kernel) were incinerated in a muffle furnace and made into ash, which were then digested with $\mathrm{HNO}_{3}+30 \% \mathrm{H}_{2} \mathrm{O}_{2}$ and prepared the solutions.

\subsection{Preparation of Sample by Microwave Digestion Method}

The samples were prepared by the microwave digestion method as previously described ${ }^{22}$. Briefly, 
all extracts were weighed accurately and transferred into seven fluorocarbon microwave vessels. Next, 10 ml concentrated $\mathrm{HNO}_{3}$ was added to each vessel. The vessels were sealed and properly placed in the microwave system (Anton Paar microwave digester). A blank sample was also prepared simultaneously by placing $10 \mathrm{ml}$ of concentrated $\mathrm{HNO}_{3}$ in one of the empty fluorocarbon microwave vessel and placed it in the microwave system after sealing it tightly. All the samples and blank were digested at $175^{\circ} \mathrm{C}$ for 10 minutes. After cooling it to a sufficient time, carefully uncapped and vented each vessel in fume cupboard. Contents of each vessel then transferred to $50 \mathrm{ml}$ volumetric flask and made up to the mark with Mille$\mathrm{Q}$ water.

\subsection{Preparation of Reference Standard Solution} Standard solutions of each element were separately prepared using reference standard metal solutions. The procedure followed was as per the Analysis Guidebook of Shimadzu Solutions for Science. The solutions prepared were placed in tightly capped plastic bottles and used within a day of their preparation.

\subsection{Preparation of Reagent Blank Solution}

$10 \mathrm{ml}$ of conc. nitric acid and $2 \mathrm{ml}$ of $30 \% \mathrm{H}_{2} \mathrm{O}_{2}$ were quantitatively added into $50 \mathrm{ml}$ volumetric flaks and diluted with de-ionized water to the mark. These solutions were served as blank solution.

\subsection{Determination of Elements Concentration}

Elemental profile of $T$. bellirica was determined quantitatively by Inductively Coupled Plasma Optical Emission Spectroscopy (ICP-OES) (VARIAN INC. - liberty series, axial viewed plasma, sequential type ICP-OES spectrometer, wavelength range 189-940 $\mathrm{nm}$ ). Using reference standards, the calibration curves were obtained for all the elements. The sample solutions were adequately diluted to keep the absorbance in the linear range of measurement.

\subsection{Statistical Analysis}

All assays were carried out in triplicates and values were obtained by calculating the average of five experiments. Data are presented as mean \pm SEM.

The SEM is calculated by dividing the SD $(\sigma)$ by the square root of $n$ (number of samples).
The formula to find the sample mean

$$
\mu_{x}=\frac{\sum_{1}^{n} x_{i}}{n}
$$

Formula to estimate sample standard deviation

$$
s=\sqrt{\frac{\sum_{1}^{n}\left(x_{i}-\mu_{x}\right)^{2}}{n-1}}
$$

Formula to estimate standard error (SE) of mean

$$
s E_{\mu_{x}}=\frac{s}{\sqrt{n}}
$$

\section{Results and Discussion}

An appropriate preparation method was chosen, a simultaneous quantitative mineralization and dissolution made by using relevant chemical reagents and physical means. Partial dissolution could occur due to high contents of silicates and that may lead to poor recoveries of many elements, especially those that are relatively abundant in plant media and partly associated with silicate. Besides aluminum and other elements such as $\mathrm{Fe}$ and $\mathrm{B}$ also results in poor recoveries in case of incomplete dissolution of sample. After the preparation procedure applied in this work, the sample matrix was largely simplified and the resulting solution was found to be clear, colorless, and odorless with no observed residues and ensuring complete dissolution was achieved in most cases.

With regard to ICP analysis, no specific precautions have to be taken as long as the measured concentrations satisfy specific criteria like sensitivity, detection limits, and working range. Moreover, avoiding interfering substances is of great importance. With regard to ICP-OES analysis, the procedure should be performed under the optimal plasma conditions. The detection limits of ICP-OES are of $\mathrm{mg} / \mathrm{l}$ depending on the element of choice and thus enable quantification. The above method of analysis should be validated with the methods to CRM (NIST 1573 - tomato leaves) from mineralization, dissolution, and measurements. ICP-OES analysis revealed that the found values were very close to the certified values of the examined elements (Table 3 )

Table 3. Concentration values of elements of CRM (NIST 1573 - tomato leaves) in $\mathrm{mg} / \mathrm{kg}$.

\begin{tabular}{|c|c|c|c|}
\hline Element & $\begin{array}{c}\text { Found Value } \\
(\mathbf{m g} / \mathbf{k g})\end{array}$ & $\begin{array}{c}\text { Certified Value } \\
(\mathbf{m g} / \mathbf{k g})\end{array}$ \\
\hline $\mathbf{C u}$ & 7.55 & $4.70 \pm 0.14$ & 160.6 \\
\hline $\mathbf{Z n}$ & 36.43 & $30.9 \pm 0.70$ & 117.9 \\
\hline $\mathbf{M n}$ & 225.8 & $246 \pm 8.00$ & 91.8 \\
\hline Fe & 304.0 & $368 \pm 7.00$ & 82.6 \\
\hline Co & 0.64 & $0.57 \pm 0.04$ & 112.3 \\
\hline
\end{tabular}




\begin{tabular}{|c|c|c|c|}
\hline $\mathbf{C r}$ & 2.23 & $1.99 \pm 0.06$ & 112.2 \\
\hline $\mathbf{N i}$ & 0.90 & $1.59 \pm 0.04$ & 56.60 \\
\hline $\mathbf{P b}$ & 1.04 & Not available & Not available \\
\hline $\mathbf{C a}$ & 5000 & $5005 \pm 90$ & 101.0 \\
\hline $\mathbf{A l}$ & 526.4 & $598 \pm 2.00$ & 88.03 \\
\hline $\mathbf{C d}$ & 1.33 & $1.52 \pm 0.03$ & 87.5 \\
\hline $\mathbf{N a}$ & 2460 & $2700 \pm 50$ & 91.1 \\
\hline
\end{tabular}

Simultaneously, an external calibration was also carried out and statistical parameters like regression and correlation analysis were performed and found the correlation coefficient(r) value in the range of 0.9981-0.9999. The results of elemental analysis of the aqueous extracts of $T$. bellirica fruit (TBE-1, TBE-2, TBE-3, and TBE-4) and the finished products of $T$. bellirica (TBF-1, TBF-2, and TBF-3) are shown in Table 4 and Table 5 , respectively.

Table 4. Elemental composition of the aqueous extracts of $T$. bellirica fruit (TBE-1, TBE-2, TBE-3, and TBE-4).

\begin{tabular}{|c|c|c|c|c|}
\hline Element & TBE-1 (mg/kg) & TBE-2 (mg/kg) & TBE-3 (mg/kg) & TBE-4 (mg/kg) \\
\hline $\mathbf{C a}$ & $723.51 \pm 0.010$ & $762.54 \pm 0.010$ & $787.39 \pm 0.008$ & $742.74 \pm 0.005$ \\
\hline Mg & $415.63 \pm 0.097$ & $467.56 \pm 0.003$ & $433.49 \pm 0.013$ & $424.24 \pm 0.003$ \\
\hline $\mathbf{N a}$ & $636.79 \pm 0.000$ & $615.43 \pm 0.003$ & $624.36 \pm 0.009$ & $603.45 \pm 0.014$ \\
\hline $\mathbf{K}$ & $156.86 \pm 0.024$ & $165.73 \pm 0.017$ & $151.23 \pm 0.012$ & $154.45 \pm 0.008$ \\
\hline Al & $43.1650 \pm 0.003$ & $39.3160 \pm 0.026$ & $47.3870 \pm 0.037$ & $53.3760 \pm 0.045$ \\
\hline B & $3.6556 \pm 0.0010$ & $2.9445 \pm 0.0008$ & $4.1345 \pm 0.0014$ & $2.7600 \pm 0.0005$ \\
\hline $\mathbf{B a}$ & $1.0241 \pm 0.0008$ & $1.0823 \pm 0.0014$ & $1.0837 \pm 0.0015$ & $1.0923 \pm 0.0018$ \\
\hline Cd & $0.0600 \pm 0.0005$ & $0.0400 \pm 0.0003$ & $0.0500 \pm 0.0004$ & $0.0600 \pm 0.0005$ \\
\hline Co & $0.0137 \pm 0.0001$ & $0.0277 \pm 0.0003$ & $0.0349 \pm 0.0005$ & $0.0146 \pm 0.0002$ \\
\hline $\mathrm{Cr}$ & $0.0489 \pm 0.0008$ & $0.0527 \pm 0.0011$ & $0.0515 \pm 0.0010$ & $0.0493 \pm 0.0010$ \\
\hline $\mathbf{C u}$ & $1.1494 \pm 0.003$ & $1.1087 \pm 0.025$ & $1.1097 \pm 0.027$ & $1.1503 \pm 0.022$ \\
\hline $\mathbf{F e}$ & $3.1559 \pm 0.041$ & $3.2974 \pm 0.062$ & $3.2815 \pm 0.048$ & $3.3074 \pm 0.075$ \\
\hline $\mathbf{L i}$ & $0.4829 \pm 0.0028$ & $0.4935 \pm 0.0029$ & $0.4318 \pm 0.0025$ & $0.4719 \pm 0.0028$ \\
\hline Mn & $2.7114 \pm 0.000$ & $2.7700 \pm 0.000$ & $2.9200 \pm 0.005$ & $2.8600 \pm 0.003$ \\
\hline Mo & $0.0119 \pm 0.0012$ & $0.0213 \pm 0.0022$ & $0.0135 \pm 0.0013$ & $0.0157 \pm 0.0018$ \\
\hline $\mathbf{N i}$ & $0.0802 \pm 0.0008$ & $0.0754 \pm 0.0007$ & $0.0954 \pm 0.0010$ & $0.0698 \pm 0.0005$ \\
\hline $\mathbf{P}$ & $0.2946 \pm 0.0015$ & $0.3457 \pm 0.0019$ & $0.2765 \pm 0.0012$ & $0.3249 \pm 0.0017$ \\
\hline $\mathbf{P b}$ & $0.6347 \pm 0.0010$ & $0.6328 \pm 0.0008$ & $0.5327 \pm 0.0006$ & $0.5328 \pm 0.0006$ \\
\hline $\mathbf{R b}$ & $152.86 \pm 0.0085$ & $160.86 \pm 0.0089$ & $152.86 \pm 0.0085$ & $155.65 \pm 0.0087$ \\
\hline $\mathbf{S}$ & $0.0267 \pm 0.0004$ & $0.0261 \pm 0.0004$ & $0.0235 \pm 0.0003$ & $0.0219 \pm 0.0001$ \\
\hline Se & $0.3961 \pm 0.0013$ & $0.3912 \pm 0.0011$ & $0.4019 \pm 0.0015$ & $0.4170 \pm 0.0017$ \\
\hline $\mathbf{S i}$ & $7.6356 \pm 0.0036$ & $7.7570 \pm 0.0038$ & $7.9767 \pm 0.0047$ & $7.4246 \pm 0.0032$ \\
\hline Sn & $0.1811 \pm 0.0008$ & $0.1834 \pm 0.0010$ & $0.1891 \pm 0.0012$ & $0.1795 \pm 0.0006$ \\
\hline $\mathrm{Sr}$ & $8.6401 \pm 0.0024$ & $8.4790 \pm 0.0021$ & $8.4387 \pm 0.0016$ & $8.4437 \pm 0.0018$ \\
\hline Te & $0.3223 \pm 0.0005$ & $0.4308 \pm 0.0014$ & $0.3483 \pm 0.0009$ & $0.3454 \pm 0.0008$ \\
\hline $\mathbf{T i}$ & $7.1562 \pm 0.0023$ & $7.1593 \pm 0.0025$ & $7.5640 \pm 0.0038$ & $7.5757 \pm 0.0041$ \\
\hline $\mathbf{V}$ & $0.0115 \pm 0.0002$ & $0.0124 \pm 0.0003$ & $0.0138 \pm 0.0005$ & $0.0153 \pm 0.0009$ \\
\hline $\mathbf{Z n}$ & $1.3426 \pm 0.0013$ & $1.4532 \pm 0.0021$ & $1.3679 \pm 0.0018$ & $1.9345 \pm 0.0037$ \\
\hline
\end{tabular}

An examination of the data from Table 4 reveals that this medicinal plant containing elements like $\mathrm{K}, \mathrm{Mg}$, $\mathrm{Mn}, \mathrm{Na}, \mathrm{B}, \mathrm{Ba}, \mathrm{Fe}, \mathrm{Zn}, \mathrm{Cu}, \mathrm{Cl}, \mathrm{Al}, \mathrm{Cr}, \mathrm{Ca}, \mathrm{Cd}, \mathrm{Ni}, \mathrm{P}$, $\mathrm{Pb}, \mathrm{S}, \mathrm{Se}, \mathrm{Sn}, \mathrm{Sr}, \mathrm{Si}, \mathrm{Te}, \mathrm{Ti}$, and $\mathrm{V}$ in different proportions. All the chosen elements were analyzed by ICP-OES instrument by measuring the absorbance of the species at its resonance wavelength. The variation in elemental concentration is mainly 
attributed to the differences in botanical structure, as well as in the mineral composition of the soil in which the plants were cultivated ${ }^{23}$. Other factors responsible for a variation in elemental concentration are preferential absorbability of the plant, use of fertilizers, irrigation water and climatic conditions ${ }^{24}$. The active constituents of the medicinal plants are the metabolic products of the plant cells. A number of trace elements play important roles in metabolism, and they are essential for successful catalysis.

Table 5. Elemental composition of the finished products of T. bellirica (TBF-1, TBF-2, and TBF-3).

\begin{tabular}{|c|c|c|c|}
\hline Element & TBF-1 (mg/kg) & TBF-2 (mg/kg) & TBF-3 (mg/kg) \\
\hline $\mathbf{C a}$ & $347.80 \pm 0.142$ & $478.90 \pm 0.217$ & $386.50 \pm 0.194$ \\
\hline Mg & $155.40 \pm 0.114$ & $194.50 \pm 0.165$ & $163.80 \pm 0.123$ \\
\hline $\mathbf{N a}$ & $290.45 \pm 0.259$ & $370.00 \pm 0.328$ & $241.76 \pm 0.209$ \\
\hline $\mathbf{K}$ & $154.40 \pm 0.172$ & $132.70 \pm 0.131$ & $142.45 \pm 0.156$ \\
\hline Al & $15.456 \pm 0.055$ & $12.657 \pm 0.028$ & $13.654 \pm 0.037$ \\
\hline B & $1.2956 \pm 0.0022$ & $1.3856 \pm 0.0033$ & $1.2567 \pm 0.0019$ \\
\hline $\mathbf{B a}$ & $0.5640 \pm 0.0046$ & $0.6543 \pm 0.0057$ & $0.5876 \pm 0.0050$ \\
\hline Cd & $0.0100 \pm 0.0001$ & $0.0158 \pm 0.0003$ & $0.0186 \pm 0.0006$ \\
\hline Co & $0.0165 \pm 0.0010$ & $0.0197 \pm 0.0017$ & $0.0178 \pm 0.0013$ \\
\hline $\mathrm{Cr}$ & $0.0105 \pm 0.0023$ & $0.0130 \pm 0.0037$ & $0.0126 \pm 0.0031$ \\
\hline $\mathrm{Cu}$ & $0.3954 \pm 0.0135$ & $0.4254 \pm 0.0147$ & $0.3354 \pm 0.0113$ \\
\hline $\mathbf{F e}$ & $1.4265 \pm 0.0275$ & $1.4676 \pm 0.0291$ & $1.3778 \pm 0.0315$ \\
\hline $\mathbf{L i}$ & $0.1400 \pm 0.0016$ & $0.1700 \pm 0.0028$ & $0.1100 \pm 0.0012$ \\
\hline Mn & $0.9873 \pm 0.0120$ & $0.8765 \pm 0.0082$ & $0.9543 \pm 0.0107$ \\
\hline Mo & $0.0976 \pm 0.0073$ & $0.0877 \pm 0.0061$ & $0.0765 \pm 0.0054$ \\
\hline $\mathbf{N i}$ & $0.0770 \pm 0.0015$ & $0.0840 \pm 0.0024$ & $0.0710 \pm 0.0013$ \\
\hline $\mathbf{P}$ & $0.1974 \pm 0.0011$ & $0.2015 \pm 0.0009$ & $0.1843 \pm 0.0012$ \\
\hline $\mathbf{P b}$ & $0.2456 \pm 0.0135$ & $0.3876 \pm 0.0146$ & $0.4567 \pm 0.0158$ \\
\hline Se & $0.1543 \pm 0.0105$ & $0.1238 \pm 0.0073$ & $0.1287 \pm 0.0176$ \\
\hline $\mathbf{S i}$ & $0.4270 \pm 0.0143$ & $0.3970 \pm 0.0131$ & $0.4730 \pm 0.0152$ \\
\hline Sn & $0.0180 \pm 0.0012$ & $0.0220 \pm 0.0017$ & $0.0230 \pm 0.0019$ \\
\hline $\mathrm{Sr}$ & $1.2754 \pm 0.0172$ & $1.3546 \pm 0.0215$ & $1.2137 \pm 0.0156$ \\
\hline Te & $0.0190 \pm 0.0016$ & $0.0120 \pm 0.0011$ & $0.0260 \pm 0.0027$ \\
\hline $\mathbf{T i}$ & $1.5300 \pm 0.0341$ & $1.6700 \pm 0.0475$ & $1.4100 \pm 0.0292$ \\
\hline $\mathbf{V}$ & $0.0086 \pm 0.0009$ & $0.0092 \pm 0.0010$ & $0.0100 \pm 0.0012$ \\
\hline $\mathbf{Z n}$ & $4.4000 \pm 0.0572$ & $3.0000 \pm 0.0433$ & $4.9000 \pm 0.0631$ \\
\hline
\end{tabular}

Trace elements or micronutrients are essential to human life and they are supplemented in the form of minerals and vitamins. These can work as co-factors of enzyme synthesis and plays a vital role in organizing the cell structure and its membrane. Trace element are toxic when its optimum levels exceeds and lead to metabolic disorders when it is deficient ${ }^{25}$. In total, these trace elements are most important for human metabolism. These elements are crucial for normal biological processes such as metabolism, growth, and development.

Table 6. The mineral composition of the alcoholic extract of $T$. bellirica fruit.

\begin{tabular}{|c|c|}
\hline Element & Composition (mg/kg) \\
\hline Ca & $50.72 \pm 1.77$ \\
\hline Mg & $18.76 \pm 0.12$ \\
\hline $\mathrm{Na}$ & $9.58 \pm 0.03$ \\
\hline $\mathbf{K}$ & $4.26 \pm 0.01$ \\
\hline $\mathbf{P}$ & $1.85 \pm 0.02$ \\
\hline $\mathbf{F e}$ & $7.59 \pm 0.05$ \\
\hline Mn & $0.10 \pm 0.01$ \\
\hline
\end{tabular}




\begin{tabular}{|l|c|}
\hline $\mathbf{Z n}$ & $0.13 \pm 0.01$ \\
\hline $\mathbf{P b}$ & $0.02 \pm 0.01$ \\
\hline $\mathbf{C d}$ & $0.01 \pm 0.01$ \\
\hline $\mathbf{N a} / \mathbf{K}$ & 0.51 \\
\hline $\mathbf{C a} / \mathbf{P}$ & 6.68 \\
\hline
\end{tabular}

Table 7. The comparative mineral composition of the alcoholic extracts of $T$. bellirica seed oil and seed kernel.

\begin{tabular}{|l|c|c|}
\hline Element & Composition $(\mathbf{m g} / \mathbf{k g})$ & Composition $\mathbf{( m g} / \mathbf{k g})$ \\
\hline $\mathbf{C a}$ & 120 & 300 \\
\hline $\mathbf{M g}$ & 20 & 50 \\
\hline $\mathbf{N a}$ & 180 & 200 \\
\hline $\mathbf{K}$ & 200 & 1,150 \\
\hline $\mathbf{P}$ & 10 & 450 \\
\hline $\mathbf{F e}$ & 23 & 204 \\
\hline $\mathbf{M n}$ & 1 & 4 \\
\hline $\mathbf{Z n}$ & 12 & 54 \\
\hline $\mathbf{C u}$ & 12 & 50 \\
\hline
\end{tabular}

The values shown in Table 7 indicate that the T. bellirica exhibits a high nutritional value, and hence, it can be an essential supplement to living organisms. Further evidence clearly indicates that the alcoholic extracts of $T$. bellirica seed oil and seed kernel is highly suitable for edible purpose and it is most preferred in comparison to other seed oils.

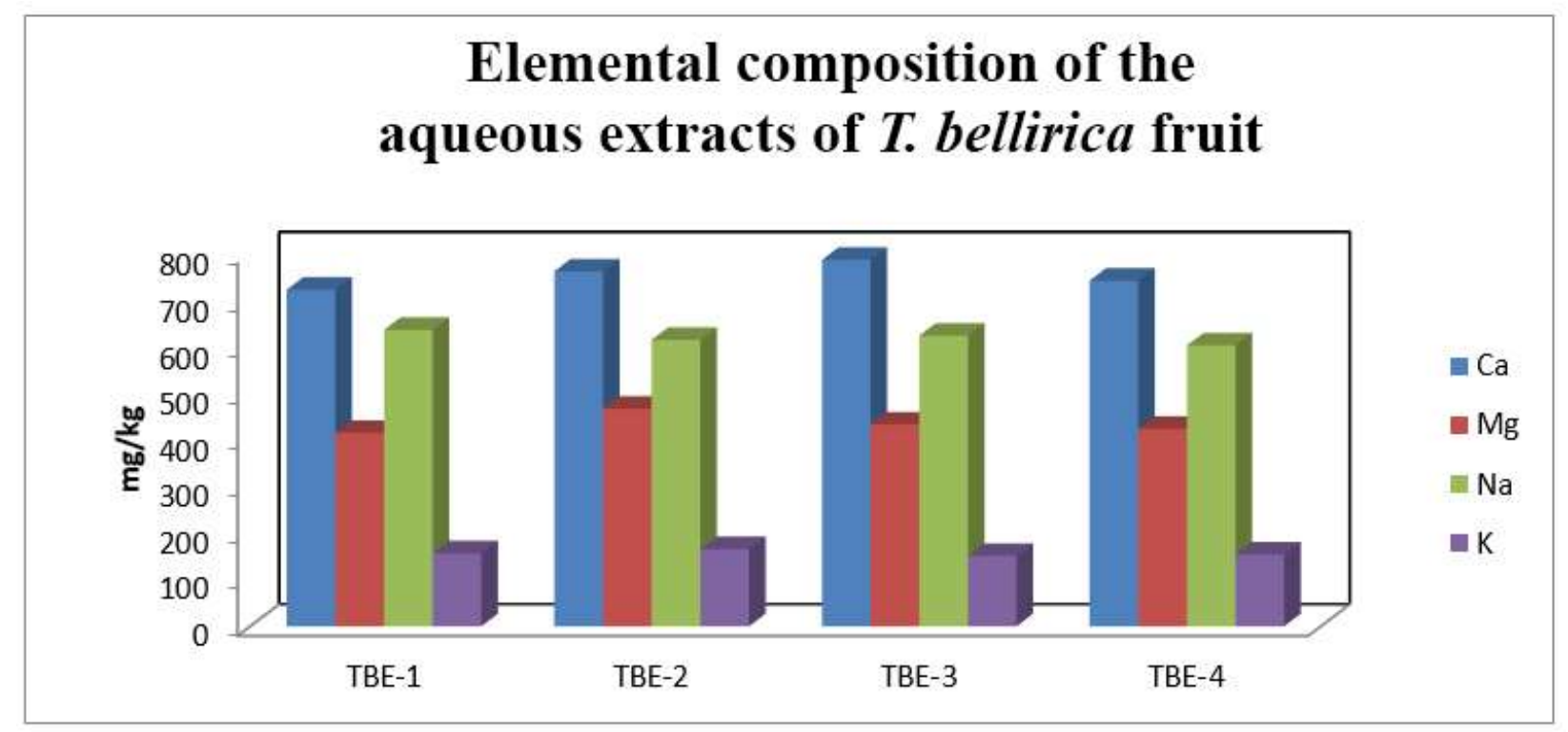

Figure 1. Elemental composition of the aqueous extracts of T. bellirica fruit (TBE-1, TBE-2, TBE-3, and TBE-4) [Ca, $\mathrm{Na}, \mathrm{Mg}$, and $\mathrm{K}]$.

$\mathrm{Ca}$ is the most abundant macro element in all tested T. bellirica extracts (Tables 4-7, Figure 1, and Figure 2). T. bellirica is one of the best bone healing medicinal herbs ${ }^{26}$. Ca is a vital element in building and maintaining strong bones and teeth. It is essential for blood clotting, maintenance of blood pressure and as a cofactor in enzymatic processes ${ }^{27}$. Proper use of Ca supplements with vitamin $\mathrm{K} 2$ as a promoter of bone and cardiovascular health ${ }^{28}$. The high concentration of $\mathrm{Ca}$ in $T$. bellirica fruit makes it a good source of nutrients for the elderly who are predisposed to osteoporosis since Ca provides rigidity to bones.

Ca plays an important role in many metabolic processes. Ca deficiency gives rise osteoporosis ${ }^{29}$. Ca content in the aqueous extracts of $T$. bellirica fruit is $754.05 \mathrm{mg} / \mathrm{kg}, 723.51 \mathrm{mg} / \mathrm{kg}$ (TBE-1) being the lowest amount and $787.39 \mathrm{mg} / \mathrm{kg}$ (TBE-3) being the highest amount (Table 4). Ca content in the finished products of $T$. bellirica is $404.40 \mathrm{mg} / \mathrm{kg}, 347.80$ $\mathrm{mg} / \mathrm{kg}$ (TBF-1) being the lowest amount and 478.90 $\mathrm{mg} / \mathrm{kg}$ (TBF-2) being the highest amount (Table 5). 
Ca content in the alcoholic extract of $T$. bellirica fruit was found to be $50.72 \mathrm{mg} / \mathrm{kg}$ (Table 6). Ca content in the alcoholic extracts of $T$. bellirica seed oil and seed kernel was found to be $300 \mathrm{mg} / \mathrm{kg}$ and $120 \mathrm{mg} / \mathrm{kg}$, respectively (Table 7). Generally, not distinguished much variation between TBE- 1 to TBE-4 but there is a noticeable amount of one of the formulation that is $193.50 \mathrm{mg} / \mathrm{kg}$ (TBF-2). In the alcoholic extract of $T$. bellirica fruit, $\mathrm{Mg}$ was found to be $18.76 \mathrm{mg} / \mathrm{kg}$. $\mathrm{Mg}$ was found to be $20 \mathrm{mg} / \mathrm{kg}$ and $50 \mathrm{mg} / \mathrm{kg}$ in the alcoholic extracts of $T$. bellirica seed oil and seed kernel, respectively.

\section{Elemental composition of T. bellirica finished products}

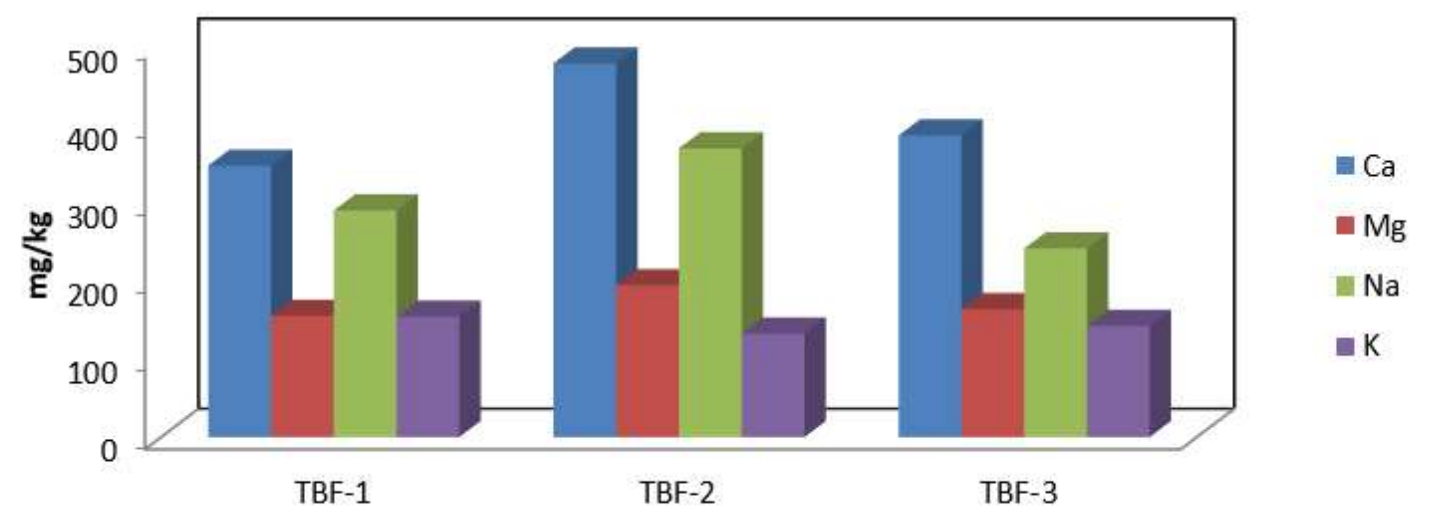

Figure 2. Elemental composition of the finished products of T. bellirica (TBF-1, TBF-2, and TBF-3) $[\mathrm{Ca}, \mathrm{Mg}, \mathrm{Na}$, and $\mathrm{K}]$.

$\mathrm{Mg}$ has several biological functions in the human body including its role as a cofactor for more than 300 enzymatic reactions ${ }^{30}$. In clinical practice, optimizing $\mathrm{Mg}$ through diet and supplementation appears to be a safe, useful, and well-documented therapy for several medical conditions ${ }^{31}$. The values determined for the aqueous extracts of $T$. bellirica fruit are the best source for higher $\mathrm{Mg}$ content determination. $\mathrm{Mg}$ is a strongly electropositive, mobile, abundant divalent element for plants, with an average requirement for optimal plant growth in the range of $0.5-1.0 \%{ }^{32} . \mathrm{Mg}$ is the third most abundant macro element in the aqueous extracts of $T$. bellirica fruit (Table 4 and Figure 1) and the finished products of $T$. bellirica (Table 5 and Figure 2). Mg content in the aqueous extracts of $T$. bellirica fruit was found to be in the range of 415.63-467.56 mg/kg (Table 4). Mg content in the finished products of T. bellirica was found to be in the range of $155.40-194.50 \mathrm{mg} / \mathrm{kg}$ (Table 5). $\mathrm{Mg}$ content in the alcoholic extract of T. bellirica fruit was found to be $18.76 \mathrm{mg} / \mathrm{kg}$ (Table 6). $\mathrm{Mg}$ content in the alcoholic extracts of $T$. bellirica seed oil and seed kernel was found to be $20 \mathrm{mg} / \mathrm{kg}$ and $50 \mathrm{mg} / \mathrm{kg}$, respectively (Table 7).

$\mathrm{Na}$ and $\mathrm{K}$ levels in the aqueous extracts of $T$. bellirica leaves were reported to be higher than those in the aqueous extracts of $T$. bellirica fruits $(62 \mathrm{mg} / 100 \mathrm{~g}$ and $15.7 \mathrm{mg} / 100 \mathrm{~g}$, respectively) ${ }^{33}$. These macro elements are required for normal functioning of the nervous system and play a vital role in regulating blood pressure. It has been recommended that $\mathrm{Na} / \mathrm{K}$ ratio less than 1.0 will prevent high blood pressure ${ }^{34}$. The Na/K-ATPase pump helps to maintain osmotic equilibrium and membrane potential in cells ${ }^{35}$. Our analysis shows that the $\mathrm{Na} / \mathrm{K}$ ratio in the alcoholic extract of $T$. bellirica fruit was found to be 0.51 (Table 6 ), which is in conformity with the recommended ratio.

$\mathrm{Na}$ content in the aqueous extracts of $T$. bellirica fruit was found to be in the range of $603.45-636.79 \mathrm{mg} / \mathrm{kg}$ (Table 4). Na content in the finished products of $T$. bellirica was found to be in the range of 241.76$370.00 \mathrm{mg} / \mathrm{kg}$ (Table 5). Na content in the alcoholic extract of $T$. bellirica fruit was found to be $9.58 \mathrm{mg} / \mathrm{kg}$ (Table 6). Na content in the alcoholic extracts of T. bellirica seed oil and seed kernel was found to be $180 \mathrm{mg} / \mathrm{kg}$ and $200 \mathrm{mg} / \mathrm{kg}$, respectively (Table 7).

$\mathrm{K}$ content in the aqueous extracts of $T$. bellirica fruit was found to be in the range of $151.23-165.73 \mathrm{mg} / \mathrm{kg}$ (Table 4). K content in the finished products of T. bellirica was found to be in the range of 132.70$154.40 \mathrm{mg} / \mathrm{kg}$ (Table 5). $\mathrm{K}$ content in the alcoholic extract of T. bellirica fruit was found to be $4.26 \mathrm{mg} / \mathrm{kg}$ (Table 6). $\mathrm{K}$ content in the alcoholic extracts of $T$. bellirica seed oil and seed kernel was found to be $200 \mathrm{mg} / \mathrm{kg}$ and $1,150 \mathrm{mg} / \mathrm{kg}$, respectively (Table 7). Clearly, $\mathrm{K}$ content in the seed kernel is much higher than that in the seed oil. 


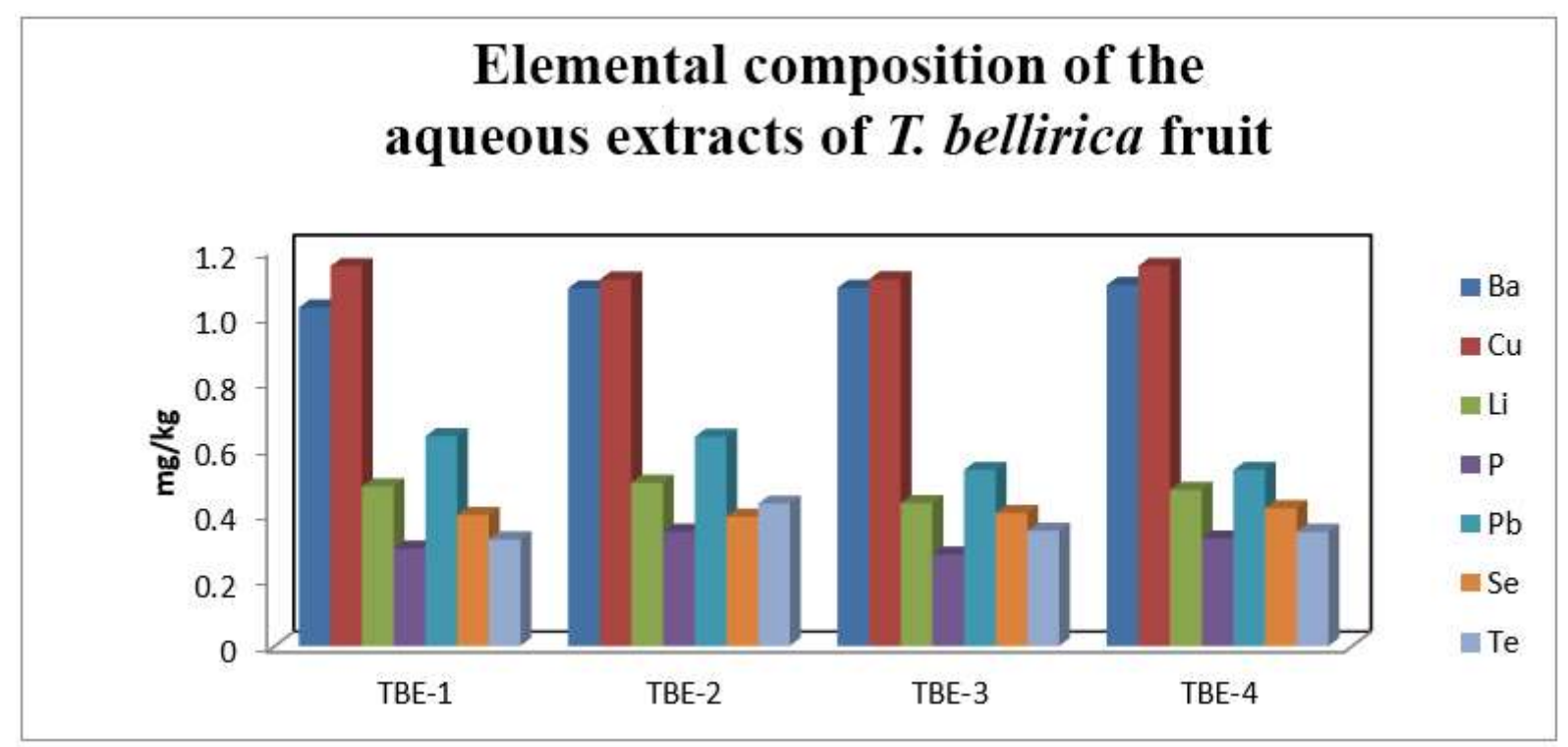

Figure 3. Elemental composition of the aqueous extracts of $T$. bellirica fruit (TBE-1, TBE-2, TBE-3, and TBE-4) [Ba, Cu, Li, P, Pb, Se and Te].

$\mathrm{P}$ is one of the most abundant minerals in the human body, second only to $\mathrm{Ca}^{36}$. This essential mineral is required for the healthy formation of bones and teeth, and is necessary for our bodies to process many of the foods that we eat. $\mathrm{P}$ is part of the body's energy storage system, and it helps maintain normal blood sugar levels ${ }^{36}$. The proper heart functioning, cell growth, and tissue repair processes require adequate amounts of $\mathrm{P}$ in the body ${ }^{36}$. $\mathrm{P}$ content in the aqueous extracts of $T$. bellirica fruit was found to be in the range of $0.2765-0.3457 \mathrm{mg} / \mathrm{kg}$ (Table 4). P content in the finished products of $T$. bellirica was found to be in the range of $0.1843-0.2015 \mathrm{mg} / \mathrm{kg}$ (Table 5). P content in the alcoholic extract of $T$. bellirica fruit was found to be $1.85 \mathrm{mg} / \mathrm{kg}$ (Table 6). P content in the alcoholic extracts of $T$. bellirica seed oil and seed kernel was found to be $10 \mathrm{mg} / \mathrm{kg}$ and $450 \mathrm{mg} / \mathrm{kg}$, respectively
(Table 7). Clearly, P content in the seed kernel is much higher than that in the seed oil.

The levels of $\mathrm{Mg}, \mathrm{P}, \mathrm{Fe}, \mathrm{Mn}$, and $\mathrm{Zn}$ in T. bellirica fruit are higher than those reported for other Combretaceae such as T. Arjuna ${ }^{27}$ and T. chebula ${ }^{37}$. These elements are essential components of immune system and are vital for the synthesis of hemoglobin ${ }^{27}$. A food sample is considered to be valuable if the $\mathrm{Ca} / \mathrm{P}$ ratio is greater than 1.0 and poor if it is less than $0.5^{38}$. This is because a $\mathrm{Ca} / \mathrm{P}$ ratio above 2.0 helps in the absorption of $\mathrm{Ca}$ in the small intestine. Moreover, the $\mathrm{Ca} / \mathrm{P}$ ratio is as essential tool for the diagnosis of primary hyperparathyroidism and is of greater significance compared to serum $\mathrm{Ca}$ level. ${ }^{38}$ As shown in Table 6 , the $\mathrm{Ca} / \mathrm{P}$ ratio in the alcoholic extract of $T$. bellirica fruit was found to be 6.68 .

\section{Elemental composition of the aqueous extracts of $T$. bellirica fruit}

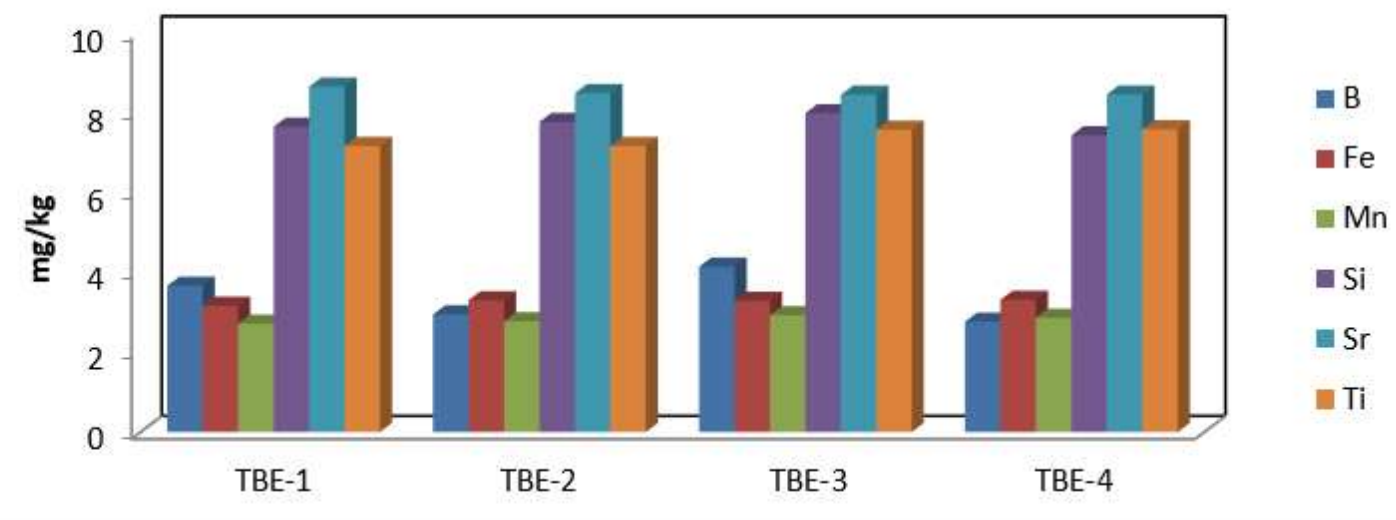

Figure 4. Elemental composition of the aqueous extracts of $T$. bellirica fruit (TBE-1, TBE-2, TBE-3, and TBE-4) [B, Fe, Mn, Si, Sr, and Ti]. 
The micro elements (B, Fe, $\mathrm{Mn}, \mathrm{Si}, \mathrm{Sr}$, and $\mathrm{Ti}$ ) are present in different amounts in the aqueous extracts of T. bellirica fruit (Table 4 and Figure 4) and the finished products of $T$. bellirica (Table 5). B is necessary for the brain to function properly and can increase mental alertness. Without small amounts of $\mathrm{B}$, bones would slowly break down and become brittle ${ }^{39}$. B is a trace element capable of providing proper bone growth and development ${ }^{40}$. B positively influences minerals such as $\mathrm{Ca}, \mathrm{P}$, and $\mathrm{Mg}$, and it acts in synergy with vitamin $\mathrm{D}^{40}$. B content in the aqueous extracts of $T$. bellirica fruit was found to be in the range of $2.76-3.65 \mathrm{mg} / \mathrm{kg}$ (Table 4). B content in the finished products of $T$. bellirica was found to be in the range of $1.25-1.38 \mathrm{mg} / \mathrm{kg}$ (Table 5). B content in the alcoholic extract of $T$. bellirica fruit and the alcoholic extracts of $T$. bellirica seed oil and seed kernel was below the detection limit.

$\mathrm{Fe}$ plays a critical role in oxygen binding to hemoglobin and in blood formation ${ }^{41}$. According to WHO (1997), two billion of the world's population are living with Fe-deficiency anemia. $\mathrm{Fe}$ is an indispensable constituent of heme-carrying proteins like cytochromes and $\mathrm{Fe}-\mathrm{S}$ proteins ${ }^{42}$. Both in plants and animals, Fe plays an important role in electron transport system during cellular respiration ${ }^{42}$. Fe content in the aqueous extracts of T. bellirica fruit was found to be in the range of $3.1559-3.3074 \mathrm{mg} / \mathrm{kg}$ (Table 4). Fe content in the finished products of T. bellirica was found to be in the range of 1.3778$1.4676 \mathrm{mg} / \mathrm{kg}$ (Table 5). Fe content in the alcoholic extract of T. bellirica fruit was found to be $7.59 \mathrm{mg} / \mathrm{kg}$ (Table 6). Fe content in the alcoholic extracts of T. bellirica seed oil and seed kernel was found to be $23 \mathrm{mg} / \mathrm{kg}$ and $204 \mathrm{mg} / \mathrm{kg}$, respectively (Table 7). Clearly, Fe content in the seed kernel is much higher than that in the seed oil. These findings suggest that supplementation of the diet with $T$. bellirica fruits can help in combating Fe-deficiency anemia and other related health problems.

\section{Conclusion}

For decades, plant extracts are analyzed to report on their therapeutic properties based on various organic molecules present in them. Here, an attempt was made to substantiate the claims of using $T$. bellirica extracts and finished products for their therapeutic values. In addition, our aim was also to assess the presence of phytochemical molecules like alkaloids, tannins, saponins, proteins, carbohydrates, organic acids, etc. We also evaluated the presence and content of various macro and micro elements in T. bellirica extracts and finished products. The elements of various metals could be used for treating certain common health conditions like diabetes ( $\mathrm{Cr}, \mathrm{Mg}, \mathrm{V}$, etc.), anemia $(\mathrm{Fe})$, hair problems $(\mathrm{Se})$, osteoporosis and other bonerelated problems $(\mathrm{Ca})$, as well as growth and overall health (Zn). Our data supplements the claims of using $T$. bellirica extracts and finished products for their therapeutic values in various medical conditions.
T. bellirica could be used as a daily dietary supplement as a preventive and rejuvenating agent. It is a highly recommended herb for a dietary supplement either alone or in combination (Triphala Churna). It is highly beneficial for overall health care and it is available in various forms and as an ingredient in many products. The high concentration of macronutrients such as $\mathrm{Ca}, \mathrm{Mg}, \mathrm{Na}$, and $\mathrm{K}$ in the plant could be harnessed to combat nutrient deficiencies especially in the rural communities. T. bellirica is one the best bone healing herbs of choice due to having abundant quantities of $\mathrm{Ca}$ and $\mathrm{Mg}$. The macro elements $\mathrm{Na}$ and $\mathrm{K}$, which are required for normal functioning of the nervous system and play vital roles in regulating blood pressure, were also found to be abundant in all tested extracts of T. bellirica. The use of convectional medicinal drugs poses several adverse side effects on human health. Therefore, there is a need to incorporate edible phytochemicals into human diet as they are more effective, accessible, and inexpensive. The fruit samples of T. bellirica contain substantial amount of mineral elements. The elements analyzed in the present investigation will be helpful for drug prescription and at time of drug designing. The inorganic records evaluated in this study will be helpful to ensure the quality and verify adulteration of natural products in different ayurvedic formulations.

\section{References}

1- R.M. Kunwar, L. Mahat, L.N. Sharma, K.P. Shrestha, H. Kominee, R.W. Bussmann, Underutilized plant species in Far West Nepal, J Mountain Sci, 2012, 9(5), 589-600.

2- A.K. Meena, P. Bansal, S. Kumar, Plants-herbal wealth as a potential source of ayurvedic drugs, Asian J Tradit Med, 2009, 4(4), 152-170.

3- A. Deb, S. Barua, B. Das, Pharmacological activities of Baheda (Terminalia bellirica): a review, J Pharmacogn Phytochem, 2016, 5(1), 194-197.

4- I.E. Cock, The medicinal properties and phytochemistry of plants of the genus Terminalia (Combretaceae), Inflammopharmacology, 2015, 23(5), 203-229.

5- A. Gupta, R. Kumar, S. Kumar, A.K. Pandey, Pharmacological aspects of Terminalia bellirica, In: Molecular Biology and Pharmacognosy of Beneficial Plants (Eds. A.A. Mahdi, M. Abid, M.M.A.A. Khan, M.I. Ansari, R.K. Maheshwari), Lenin Media Private Limited: Delhi, India,2017, 52-64.

6- V. Kasabri, P.R. Flatt, Y.H. Abdel-Wahab, Terminalia bellirica stimulates the secretion and action of insulin and inhibits starch digestion and protein glycation in vitro, Br J Nutr, 2010, 103(2), 212-217.

7- A. Jadon, M. Bhadauria, S. Shukla, Protective effect of Terminalia bellirica Roxb. and gallic acid against carbon tetrachloride induced damage 
in albino rats, J Ethnopharmacol, 2007, 109(2), 214-218.

8- H.N. Siddiqu, Studies on Terminalia bellirica Roxb., effect on bile secretion and pharmacodynamic properties, Indian J Pharmcol, 1963, 25(9), 297-302.

9- M.P. Singh, A. Gupta, S.S. Sisodia, Ethno and modern pharmacological profile of Baheda (Terminalia bellirica): a review, Pharmaceut Chem J, 2018, 5(1), 153-162.

10- V.P. Trivedi, S. Nesamany, V.K. Sharma, A clinical study of the anti-tussive and antiasthmatic effect of Vibhitakphal Churna (Terminalia bellirica Roxb.) in the cases of KasaSwasa, J Res Ayurveda Siddha, 1979, 3(1-2), $1-8$.

11-S. Kaur, S. Arora, K. Kaur, S. Kumar, The in vitro antimutagenic activity of Triphala-an Indian herbal drug, Food Chem Toxicol, 2002, 40(4), 527-534.

12-M.C. Sabu, R. Kuttan, Anti-diabetic activity of medicinal plants and its relationship with their antioxidant property, J Ethnopharmacol, 2002, 81(2), 155-160.

13-J. Kuriakose, H.R. Lal, B. Eldhose, M.S. Latha, Comparative antioxidant properties of Terminalia bellirica (Gaertn.) Roxb. fruit extract: a component of ayurvedic formulation 'Triphala', Int J Pharm Pharmaceut Res, 2016, 7(4), 310320.

14-A.V. Singh, H. Asha, Antioxidant activity of Terminalia bellirica (Gaertn.) Roxb. of Tawang, Arunachal Pradesh, India, J Bioresources, 2017, 4(2), 65-72.

15-H.P. Shaila, A.L. Udupa, S.L. Udupa, Preventive actions of Terminalia bellirica in experimentally induced atherosclerosis, Int J Cardiol, 1995, 49(2), 101-106.

16-M. Tariq, S.J. Hussain, M. Asif, M Jahan, Protective effect of fruit extracts of Emblica officinalis (Gaertn) and Terminalia bellirica (Roxb.) in experimental myocardial necrosis in rats, Indian J Exp Biol, 1997,5(6), 485-486.

17-A. Amalraj, S. Gopi, Medicinal properties of Terminalia arjuna (Roxb.) Wight \& Arn.: A review, Medicinal properties of Terminalia Arjuna (Roxb.) Wight \& Arn.: a review, J Tradit Complement Med, 2017, 7(1), 65-78.

18-N. Kumar, S.M.P. Khurana, Phytochemistry and medicinal potential of the Terminalia bellirica Roxb. (Bahera), Indian J Nat Prod Resour, 2018, 9(2), 97-107.

19-S. Muhammad, B.A. Khan, N. Akhtar, T. Mahmood, A. Rasul, I. Hussain, H. Khan, A. Badshah, The morphology, extractions, chemical constituents and uses of Terminalia chebula: a review, J Med Plants Res, 2012, 6(29), 4772-4775.

20-F.A. Ayoob, H.M. Awad, S.M. El-Kousy, K.N. Rashed, N.H. Al-Sayed, Phytochemical and biological investigations of Terminalia bellirica Roxb. leaves, J Pharm Res, 2014, 8(4), 500-510.

21-M.N. Saraswathi, M. Karthikeyan, M. Kannan, S.

Rajasekar, Terminalia bellirica Roxb - a phytopharmacological review, Int J Res Pharm Biomed Sci, 2012, 3(1), 96-99.

22-G.M. Kumar, I. Neelam, A. Ajitha, V. Maheshwara Rao, inductively coupled plasma atomic absorption spectroscopy: an overview, Int J Pharm Res Anal, 2014, 4(8), 470-477.

23-R.N. Yadav, K. Rathore, A new cardenolide from the roots of Terminalia Arjuna Fitoterapia, 2001, 72(4), 459-461.

24-J.G. Penland, Dietary Boron, brain function, and cognitive performance, Environ Health Perspect, 1994, 102(7), 65-72.

25-K. Kawata, H. Yokoo, R. Shimazaki, S. Okabe, Classification of heavy-metal toxicity by human DNA microarray analysis, Environ Sci Technol, 2007, 41(10), 3769-3774.

26-V. Singh, Medicinal plants and bone healing, Natl J Maxillofac Surg, 2017, 8(1), 4-11.

27-I.E. Akubugwo, N.A. Obasi, G.C. Chinyere, A.E Ugbogu, Nutritional and chemical value of Amaranthus hybridus L. leaves from Afikpo, Nigeria, Afr J Biotechnol, 2007, 6(24), 2833-2839.

28-K. Maresz, Proper Calcium use: vitamin K2 as a promoter of bone and cardiovascular health, Integr Med (Encinitas), 2015, 14(1), 34-39.

29-B.E. Nordin, Osteoporosis and Calcium deficiency, Proc Nutr Soc, 1960, 19(2), 129-137.

30-A.M. Al Alawi, S.W. Majoni, H. Falhammar, Magnesium and human health: perspectives and research directions, Int J Endocrinol, 2018, 2018, $1-18$.

31-J.A. Pennington, Intakes of minerals from diets and foods: is there a need for concern? J Nutr, 1996, 126(9), 2304S-2308S.

32-G.K. Schwalfenber, S.J. Genuis, The importance of Magnesium in clinical healthcare, Scientifica (Cairo), 2017, 2017, 4179326.

33-O.T. Adepoju, E.O. Oyewole, Nutritional importance and micronutrient potentials of two non-conventional indigenous green leafy vegetables from Nigeria, Agric J, 2008, 3(5), 362-365.

34-M.H. Alderman, Salt, blood pressure and health: a cautionary tale, Int J Epidemiol, 2002, 31(2), 311-315.

35-Y. Pirahanchi, N.R. Aeddula, Physiology, sodium potassium pump (Na+ K+ pump), StatPearls Publishing: Treasure Island (FL), 2019.

36-R. Lokhande, P. Singare, M. Andhale, Study of mineral content of some ayurvedic Indian medicinal plants by neutron activation analysis and AAS techniques, J Health Sci, 2010, 4(3), 169-181.

37-F.O. Jimoh, A.A. Adedapo, A.J. Afolayan, Comparison of the nutritional value and biological activities of the acetone, methanol and 
water extracts of the leaves of Solanum nigrum and Leonotis leonorus, Food Chem Toxicol, 2010, 48(3), 964-971.

38-E.I. Adeyeye, P.A. Aye, Chemical composition and the effect of salts on the food properties of Triticum durum whole meal flour, J Nutr, 2005, 4(3), 187-196.

39-N.S. Rajurkar, B.M. Pardeshi, Analysis of some herbal plants from India used in the control of diabetes mellitus by NAA and AAS techniques, Appl Radiat Isot, 1997, 48(8), 1059-1062.
40-R. Dessordi, M.A. Navarro, Boron action in bone health, Rheumatol Orthop Med, 2017, 2(1), 1-3.

41-R. Hurrell, I. Egli, Iron bioavailability and dietary reference vales, Am J Clin Nutr, 2010, 91(5), $1461 \mathrm{~S}-1467 \mathrm{~S}$.

42-A.H. Millar, J. Whelan, K.L. Soole, D.A. Day, Organization nd regulation of mitochondrial respiration in plants, Annu Rev Plant Biol, 2011, 62, 79-104. 